\title{
Pierre Bordieu e a sociologia política
}

\author{
Kadma Marques Rodrigues \\ AnNe-Sophie Marie Frédérique Gosselin \\ BOURDIEU, P. Sobre o Estado: Cursos no \\ Collège de France (1989-1992). São Paulo: \\ Companhia das Letras, 2014.
}

Não é preciso ser cientista político para identificar a onipresença da questão do Estado, nos debates públicos e científicos contemporâneos, em nível nacional e internacional. No Brasil, a recente publicação de cursos sobre o Estado, ministrados pelo sociólogo Pierre Bourdieu, no Collège de France, entre 1989 e 1992 - e publicados, na França, 10 anos após sua morte -, leva-nos a considerar a questão de um ponto de vista sociológico. Eis a força principal desta obra póstuma, organizada e editada por ex-alunos e discípulos ${ }^{1}$ que afirmam, mais uma vez, o potencial heurístico da análise sociológica da instituição estatal, dos seus atos e da sua gênese histórica. Desta forma, entendemos que os cursos de Bourdieu representam uma valiosa contribuição à dimensão política da Sociologia.

Diferentemente de outros textos do sociólogo, cuja escrita era trabalhada incansavelmente até atingir a precisão linguística desejada, embora criticada por leitores, Sobre o Estado é marcado

1 Patrick Champagne, Rémi Lenoir, Franck Poupeau e Marie-Christine Rivière

\section{Kadma Marques Rodrigues}

Professora e coordenadora do programa de pós-graduação em sociologia da UECE kadmamarques@yahoo.com.br.

\section{$\overline{\text { ANNE-SOPHIE GosSelin }}$}

Doutora em sociologia pela Universidade de Paris Ouest Nanterre e professora da UNILAB asogoss@yahoo.br 
Kadma Marques Rodrigues e Anne-Sophie Marie Frédérique Gosselin

por um estilo oral impregnado da retórica didática do autor. Essa característica torna a obra provavelmente mais acessível para neófitos na sociologia bourdieusiana. Composto de transcrições dos cursos, a estrutura do livro retoma a cronologia das 23 aulas, sendo, assim, fiel ao desenvolvimento progressivo do pensamento do professor ao longo dos três anos de ensino. O pano de fundo desta reflexão é o contexto político francês e europeu da época - celebração do bicentenário da revolução francesa, queda do Muro de Berlim, início da guerra na Iugoslávia e dissolução deste Estado, enquanto a Europa, ao contrário, procurava se construir -, que aparece nos cursos, quando Bourdieu declara, para concluir: "fazer esse longo desvio pela gênese é dar-se algumas chances de escapar ao pensamento de Estado, o que é uma das maneiras empíricas de praticar a dúvida radical. [...] Seria possível proceder de outra forma e tomar a dissolução dos Estados" (BOURDIEU, 2014, p. 475).

\section{O ESTADO, OBJETO QUASE IMPENSÁVEL}

Logo na primeira aula, Bourdieu busca indulgência do público ao apresentar seu projeto como arriscado e "meio louco". "Quanto mais avanço em meu trabalho sobre o Estado, mais me convenço de que, se temos uma dificuldade especial em pensar esse objeto, é porque ele é - e peso minhas palavras - quase impensável" (BOURDIEU, 2014, p. 29-30). Não que seja difícil por ser complexo demais ao nosso entendimento; muito pelo contrário, a crítica do sociólogo visa a denunciar a tendência de muitos juristas, cientistas políticos e sociais a reproduzir nos seus modos de falar ou escrever as evidências que fazem com que o Estado nos seja familiar, natural, consensual, pois acreditamos nele. Retomando a definição que Durkheim aplicava à religião, o sociólogo apresenta o Estado como uma "ficção coletiva, como ilusão bem fundamentada" (BOURDIEU, 2014, p. 34).

Ao citar Durkheim e sua principal regra metodológica, a qual prega a ruptura com as prenoções e crenças aparentemente inquestionáveis, Bourdieu põe em xeque as armadilhas constantes, nas quais pode cair a tentativa de pensar o Estado, afastando-se das próprias categorias impostas pelo Estado. Essa postura típica da 
vigilância epistemológica defendida por Gaston Bachelard encontra-se de forma recorrente na preocupação do sociólogo com a linguagem, que o faz duvidar da pertinência das definições prévias que acabam tornando-se um "aparato formalista [...] contraprodutivo cientificamente" (BOURDIEU, 2014, p. 209) ou utilizar expressões aparentemente redundantes como a fórmula hoje clássica das "estruturas estruturantes" para tratar das disposições sociais.

Os cursos Sobre o Estado devem ser lidos como um ensaio didático, no qual Bourdieu mobiliza seus conceitos teóricos para demostrar a necessidade de pesquisar as manifestações do Estado, em vez de pensar o que é o Estado em uma perspectiva substancialista. Portanto, quem abrir o livro com esse tipo de expectativa, ficará decepcionado pelo que encontrará nele. Referindo-se aos clássicos da sociologia (Durkheim, Marx e Weber), que, mais uma vez, busca reconciliar, Bourdieu defende uma concepção da Sociologia como uma ciência do "desvelamento do real". Diante disto, tratar sociologicamente do Estado consiste em "descortinar" o que ele chama "de "amnésia da gênese", inerente a toda institucionalização exitosa, a toda instituição que conseguiu se impor implicando o esquecimento de sua gênese" (p. 166). Daí percebese a importância dada à história para fornecer instrumentos para desconstruir o "arbitrário dos começos". O modelo de estudo da gênese do Estado moderno apresentado nos cursos encontra-se, então, no cruzamento da História com a Sociologia e a Filosofia Política.

\section{CONSTITUIÇÃO DO CAMPO DO PODER}

Examinar com minucia essa gênese significa descrever a constituição de um campo social relativamente autônomo no interior de um mundo social, o "campo do poder, isto é, um espaço diferenciado dentro do qual os detentores de poderes diferentes lutam para que seu poder seja o poder legítimo" (BOURDIEU, 2014, p. 407). Neste sentido, os cursos sobre o Estado devem ser apreendidos como integrando o amplo projeto de Bourdieu de propor uma teoria geral dos campos, que dê conta da pluralidade dos espaços sociais que formam a sociedade. 
Kadma Marques Rodrigues e Anne-Sophie Marie FrédériQue Gosselin

Inspirando-se nas teorias de Norbert Elias e Charles de Tilly, Bourdieu descreve o processo histórico que leva à transformação do monopólio privado do poder, característico do Estado dinástico encarnado pelo rei, em monopólio público do Estado moderno. Nesta transição, o sociólogo destaca o papel fundamental dos juristas na formação de uma burocracia estatal e a emergência de corporações profissionais associadas ao desenvolvimento do chamado serviço público, inseparável, na concepção francesa, da representação do Estado moderno. A descrição tanto do desenvolvimento do aparato burocrático quanto da formação do espaço público- ambos vinculados - remete a uma concepção que enfatiza a função da institucionalização na manutenção da ordem social. Desse modo, Bourdieu inscreve-se na tradição dos filósofos do contrato social. Essa leitura ressalta também a "dupla face do Estado", isto é, a ambiguidade fundamental entre, de um lado, o projeto de integração, unificação e universalização estatal e, de outro, o processo de desapropriação, exclusão, dominação e desqualificação social e simbólica do Estado.

\section{"VIOLÊNCIA SIMBÓLICA LEGÍTIMA"}

É preciso lembrar que Bourdieu constrói seu argumento, retomando a famosa fórmula de Max Weber, a qual define o Estado como "monopólio da violência legítima" e complementando-a com uma ênfase na dimensão simbólica desta dominação. "Ele [o Estado] se estabelece através da ordem simbólica que instaura, isto é, tanto na objetividade, nas coisas [...] como na subjetividade - nas estruturas mentais sob a forma de princípios de divisões, de princípios de visão, de sistemas de classificações" (BOURDIEU, 2014, p. 165). Nesta lógica, o poder de legitimar a dominação de alguns sobre a maioria aparece inseparável da posse do capital simbólico pelas elites dirigentes, que impõem sua dominação como uma evidência, especialmente por meio de uma falsa meritocracia escolar que lhe dá diplomas para justificar sua autoridade. Neste momento, o sociólogo mobiliza as teorias desenvolvidas nas suas prévias produções sobre educação. Portanto, não se pode entender o estudo sociológico que Bourdieu faz da formação do Estado moderno 
sem retomar o processo de acumulação das diferentes espécies de capital (econômico, social, cultural, etc.) nas mãos de poucos, um processo de "concentração e metaconcentração que gera essa realidade absolutamente espantosa que é o Estado" (BOURDIEU, 2014, p. 260).

\section{DOMINAÇÃO}

Desde o primeiro curso, Bourdieu tenta responder a uma questão que não deixava de inquietá-lo: como é possível que haja tão pouca revolta face ao poder estatal? Dito de outro modo, como explicar a tácita aceitação dos dominados no exercício da violência simbólica, ou seja, a tendência dos agentes sociais a se submeterem à dominação, tendência sem a qual não existiria ordem social? Para responder a essa questão elaborada por David Hume - como é possível que os governados (numerosos) obedeçam tão facilmente aos governantes (tão poucos)? -, Bourdieu insiste sobre a dimensão simbólica da crença, que permite a legitimidade da dominação assim naturalizada. Essa preocupação remete-nos à centralidade da dominação na sociologia de Bourdieu, lembrando que as reflexões sobre o Estado só se tornam inteligíveis se forem consideradas no âmbito da teoria da dominação.

De fato, esta problemática atravessa toda a obra de Bourdieu, além dos cursos sobre o Estado. Interessante lembrar que, em 1989, antes do começo dos cursos sobre o Estado, o sociólogo publica $L a$ noblesse d'État: grandes écoles et esprit de corps, sobre os processos de legitimação, por meio do sistema escolar, das elites do poder na França dos anos 1980 e, em 1993, logo após os cursos, A miséria do mundo, que pretende dar voz aos excluídos para compreender as condições de produção da miséria social. Se o Estado como tal aparece como objeto de estudo da sua sociologia apenas ao fim dos anos 1980, Bourdieu faz da questão da dominação, enquanto fundamento do político e da ordem social, o eixo central do seu pensamento. Assim, concordamos plenamente com os editores da publicação francesa quando afirmam, ao final do volume, que "a importância do curso sobre o Estado reside, por fim, na atenção propriamente sociológica que Bourdieu dava a todas as formas 
Kadma Marques Rodrigues e Anne-Sophie Marie Frédérique Gosselin

de dominação" (BOURDIEU, 2012, p. 601). E, com Luc Boltanski (2013), notamos que "é provavelmente um traço bastante distintivo das teorias da dominação de interessar-se menos aos movimentos de rebelião ou de revolta que aos períodos durante os quais os atores sociais parecem tolerar a opressão de que são alvo. As teorias da dominação são raramente teorias da revolução".

\section{DO METACAMPO ÀS RESISTÊNCIAS}

Partindo desta observação, chamamos a atenção para a imagem elaborada por Bourdieu de um "Estado todo poderoso", um metacampo ou campo dos campos, cujos agentes têm a capacidade de agir sobre os diferentes campos. Ora, seria interessante reverter esse quadro e perguntar-se se o Estado que sujeita não está ele também sujeito a uma contestação pública. Essa reflexão mereceria uma discussão aprofundada, a partir do pensamento de Michel Foucault que, infelizmente, aparece de modo esporádico nas demostrações de Bourdieu. "Se eu dissesse doxa, vocês pensariam em disciplina, acreditariam que é a diferença com Foucault. Não gosto de praticar esse joguinho porque, se queremos praticá-lo de maneira completa, é preciso muito tempo para ser justo com as pessoas de quem nos diferenciamos. [...] Eu não tenho os meios de fazê-lo" (BOURDIEU, 2014, p. 247). Hoje, podemos lamentar que esse diálogo com Foucault não tenha sido mais explicitado pelo professor, notadamente sobre questões ligadas à coerção e à disciplina. Pensamos na potencial proximidade entre a micropolítica foucaultiana e a fenomenologia social do Estado, proposta por Bourdieu; na diferenciação entre poder e dominação; no conceito de governamentalidade, como ferramenta para captar o processo de estatização das relações de poder; ou ainda, nas estratégias de resistência, inspiradas pelo último Foucault e apenas sugeridas por Bourdieu que, porém, revelam o papel do indivíduo e das coletividades, nas lutas por transformação das estruturas de poder, gerindo pequenos e múltiplos movimentos de contestação, às vezes, decisivos para o futuro da vida sociopolítica nacional e/ ou internacional. 


\section{ARTICULAÇÃO TEORIA/EMPIRIA}

Talvez essa crítica possa ser superada pelo modo como os pesquisadores de hoje mobilizam a teoria bourdieusiana, na construção dos seus objetos específicos. Nesta perspectiva teóricoempírica, vale lembrar que o aparato conceitual bourdieusiano não deveria ser utilizado, sem questionar o contexto no qual foi elaborado e aquele no qual é aplicado hoje. Por isso, é imprescindível, no nosso entender, uma adaptação - ou melhor, uma apropriação - das análises propostas por Bourdieu, que seja coerente com as particularidades econômicas, culturais, históricas, sociais e políticas da sociedade brasileira contemporânea. Nos cursos em Sobre o Estado, Bourdieu insiste mais uma vez sobre a necessidade de construir uma relação estreita entre o pensamento teórico e a abordagem empírica. Por isso, o livro pode também ser lido como um convite à pesquisa ou uma proposta metodológica de investigação, que possibilita objetivar o espaço das posições sociais que se encontram na base da produção de uma política, como, por exemplo, o caso da pesquisa sobre a política francesa de habitação, citada várias vezes, ao longo dos cursos, e que estava sendo concluída, naquele momento.

Apesar de sua tendência estruturalista, uma das grandes forças da teoria de Bourdieu é fornecer um quadro analítico, no qual o macro não exclue a perspectiva micro. Nos cursos, ele constrói uma teoria do poder que coloca grande ênfase no que ele chama de "fenomenologia do Estado", ou seja, nos atos burocráticos cotidianos dos agentes estatais, mas também de "todos nós [que] temos o Estado na cabeça" (BOURDIEU, 2014, p. 475), quando obedecemos ou acreditamos na "magia" performativa dos atos de Estado.

A título de conclusão, consideremos que, para extrair o máximo do potencial heurístico da análise sociológica que Bourdieu faz da instituição estatal, é no mínimo prudente inserir seus cursos, no fluxo cronológico e epistemológico da produção acadêmica do autor. Assim, não apenas reavaliamos o sentido de obras precedentes, vinculadas à crescente familiaridade e interesse de Bourdieu pela dimensão política da sociologia, mas também relacionamos os cursos de Sobre o Estado a outros ministrados a 
Kadma Marques Rodrigues e Anne-Sophie Marie Frédérique Gosselin

seguir, os quais constituíram, deste modo, resposta às inquietações despertadas pela questão da transformação social em face do Estado todo-poderoso, descortinado nos anos de 1989 a 1992.

\section{REFERÊNCIAS}

BOLTANSKI, L. La sociologie est toujours critique: Le champ conceptuel de la notion de domination. In : CONGRESSO DA ASSOCIATION FRANÇAISE DE SOCIOLOGIE, 5., 2013, Nantes. [Conferência de abertura]. Anais... Disponível em : <https:// webtv.univ-nantes.fr/fiche/3619/luc-boltanski-la-sociologieest-toujours-critique-le-champ-conceptuel-de-la-notion-dedomination>. Acesso em: 11 nov. 2016.

BOURDIEU, P. Sur l'Etat: Cours au Collège de France (1989-1992). Paris: Éditions Raisons d'agir ; Éditions du Seuil, 2012. 